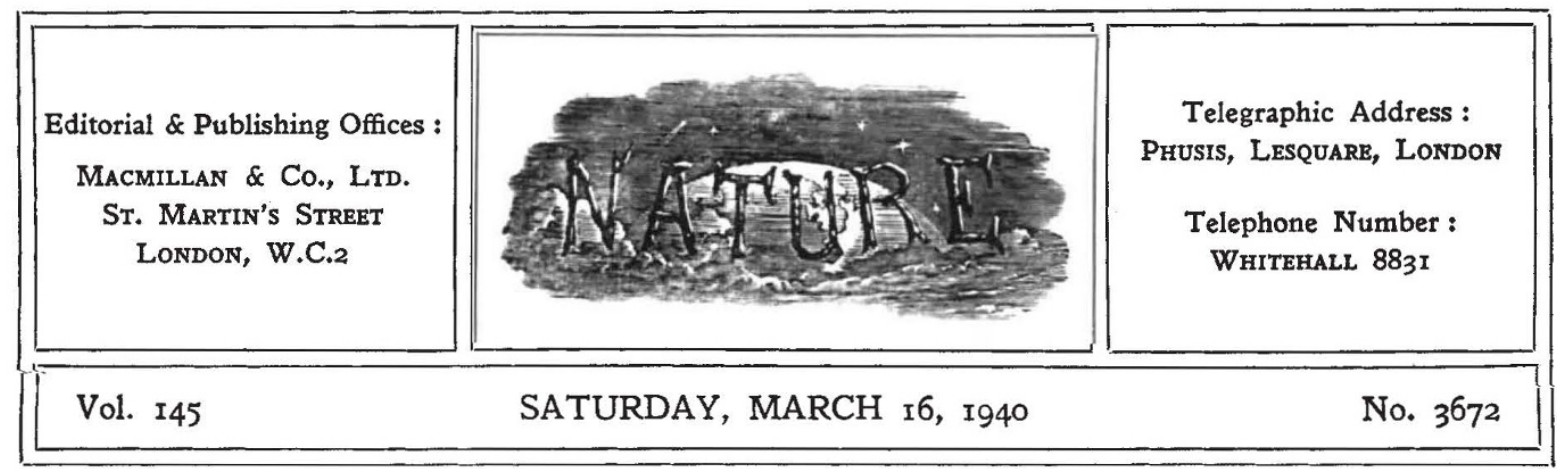

\title{
THE PLANNING OF RESEARCH
}

SOME time ago, Lord Chatfield gave a comprehensive account in the House of Lords, in reply to a question by Lord Strabolgi, of the organization of scientific knowledge and personnel in Great Britain in the prosecution of the country's war effort (NATURE, January 27, p. 134). Although speed of decision and action is vital in these days, it is perhaps as well that a fundamental question such as this should now be reviewed after an interval for reflection.

Broadly speaking, Lord Chatfield contended that the scientific talent of Great Britain is already mobilized to the best advantage. He pointed out that close contact exists between the civil directors of scientific research in the three Services, and urged that the professional ties of scientific workers who may be members of different departments would prevent departmentalism and facilitate the exchange of ideas. Lord Chatfield also laid special stress on the value of an annual review of the research work in progress in the research departments of the three Services. Similarly, pointing out that there is no central organization or clearing house for research between the three fighting Services, he considered that the existing organization is adequate to ensure that an invention gets into the hands of the appropriate expert as quickly as possible and that central organization might impose delay.

Satisfactory as this reply may be in many respects, it does not really deal with the fundamental problems which are agitating the minds of scientific workers at the present time, and indeed on some points of detail it is possible to regard Lord Chatfield as too optimistic. The demands of secrecy imposed by war-time are a serious if inevitable obstacle to the exchange of ideas, at least beyond a certain stage of development-possibly the most important of all from the point of view of practice. Moreover, there has already been a considerable curtailment of scientific meetings, which might well be rectified.

Lord Chatfield's reference to the annual review of Service research work and the dropping of longrange investigations which are not yielding immediate results, however advisable from a Service point of view particularly during war-time, touches on the first of the two major problems causing concern to scientific workers to-day. Already some science departments at the universities have adapted their research programmes in part to short-term problems which may soon be of urgent importance. In others, research has been interrupted or curtailed by transfer of staff or by requirements of the Services. In such circumstances, the problems of co-ordination between the various applied sciences and the integration of fundamental and applied research as a whole assume even greater importance. The progress of science and the needs of the present situation are daily widening the sphere of what must be regarded as practical research beyond the limits of present provisions.

Accordingly, it is being asked whether the existing structure and machinery of research are adequate to serve the needs of the country, whether in time of peace or in war. Secondly, the place and function of the universities, not merely in relation to the organization or prosecution of research, but also to the national life, are the subject of equally anxious discussion. The two questions are interlocked in numerous ways : the relation between the teaching functions and research activities of the universities: the endowment of long-range research; questions of 
professional training and training for leadership or citizenship, are all involved and in urgent need of attention.

To deal adequately with such major questions as these within the limits of a single article would be impossible, and for the moment our concern is chiefly with the adequacy of the present structure of research. This has been the subject of criticism in recent years, notably in the Memorandum on the Finance of Research prepared by the Parliamentary Science Committee, and by Prof. J. D. Bernal in "The Social Function of Science". More recently, it has been discussed by Dr. Bernard Lovell in "Science and Civilization" with the view of provoking further discussion.

A preliminary analysis of academic research was presented at the Dundee meeting of the British Association in September last, and this analysis has been included in a recent broadsheet, "The Role of Research", issued by P E P (Political and Economic Planning). Even this preliminary survey makes clear the extreme difficulty of estimating with any accuracy the man-power engaged in academic research. Research staff on a full-time basis is not readily distinguished from staff engaged in part in lecturing or demonstrating, and great difficulties are also encountered even in defining a university institution, especially in the spheres of technology and technical training.

An outstanding feature of this preliminary survey is its revelation of the insignificant provision made in universities in Great Britain for the study of descriptive and theoretical sociology. While the group of social studies as a whole is well represented, the bulk both of its staff and students is found in departments of history, economics or law; contemporary social relations are scarcely studied from any point of view wider than that of economics. An excess in the proportion of advanced students over the percentage figure for the staff is most marked in departments of chemistry, but also appears in education, history and economics. The serious strain imposed on the teaching staffs by this disproportion cannot be without effect on their research time.

This preliminary survey thus supports the numerous pleas which have been voiced for some re-orientation of research effort between the physical sciences and the social and biological sciences. The unbalanced distribution of research resources even in war-time is likely to be fraught with serious consequences, to some of which attention has been directed from the economic side.
The difficulties encountered in evacuation schemes have already indicated the need for more objective social research, and the success of rationing and other measures imposed by the national emergency may increasingly depend on accurate scientific knowledge of social needs and problems.

On this ground alone, therefore, inquiry into the present structure of research appears to be justified. It is not disputed, as Lord Chatfield urged, and as Sir Robert Robertson observed when the B.A. report was presented at Dundee, that effective machinery of co-operation exists in the Advisory Council for Scientific and Industrial Research, the Agricultural Research Council and the Medical Research Council. The improvement in this respect in the last twenty years is entirely satisfactory. What is unsatisfactory, however, is the inadequacy of the resources available for such bodies, and their limitation to advisory functions as distinct from the initiation of policy. Dr.Lovell contrasts, forexample, the $£ 195,000$ received by the Medical Research Council for research with the $£ 3,000,000$ spent every year on advertising patent medicines and the annual turnover of $£ 20,000,000$ from their sale.

A second unsatisfactory feature of the situation is the absence of a co-ordinating authority able or competent to divert available expenditure or resources from one major field to another as the need is demonstrated. Despite the established value of long-range research in providing the basis of technical advance, such fundamental research remains in the most precarious position of all. Its efficiency depends on continuity, and yet it is probably more liable to abrupt termination or interruption than any other type. The importance of provision for continuity, which is the only satisfactory guarantee that half-completed work may not be utterly wasted, can scarcely be overstressed. Something much more effective than the existing methods of co-operation is essential to initiate the rationalization necessary to bring the whole cycle of research into a comprehensive and ordered scheme.

Failure to realize the basic interdependence of research-that research, whether prosecuted in the universities, in industry or in Government departments, is not distinct but a part of the same mechanism-not only threatens to handicap the solution of problems of reconstruction in time of peace, but is also a real danger to the efficiency of our war-effort. Already it is clear that many of our difficulties in dealing with the problems of adjustment from a peace-time to a war-time economy 
are due to our past neglect of research in the social and biological sciences. Many aspects of administration and government, the directive part of man and most aspects of human values are largely untouched by scientific investigation.

It is this position which makes Lord Chatfield's account of consultation and contact between the different Service departments less reassuring than it might otherwise be. Even if there were a co-ordinating authority competent to sort out long-range investigations, discontinued as a result of the annual review of the Service departments, and ensure their continuity where desirable, we could not regard the position as satisfactory while there appears to be no means for initiating those researches on the social side, which may well have a decisive influence on national morale. It has to be remembered in this connexion that there is already a marked tendency in industry, for example, to ignore the lessons of the War of 1914-18 and the experience of the Industrial Health Research Board, as was pointed out at a recent symposium of the Industrial Section of the British Psychological Society (see Nature, February 3, 1940, p. 174).

In comparison with the position during the War of 1914-18, the organization of research, of course, represents an immense advance. The Advisory Council of the Department of Scientific and Industrial Research is very clearly alive to the danger of interrupting research, and has already deprecated any hasty reduction of work by the research associations without careful consideration of its ultimate effect on the welfare of the industries they serve. While wise adjustment of research programmes may enable the various associations to anticipate and deal with problems requiring immediate solution, the Advisory Council is anxious that fundamental investigations should be continued so far as possible. The Government, moreover, is to continue its pre-War rate of grants.

Satisfactory as this position may be, the crux of the situation is in the universities, where by far the greater proportion of fundamental research is prosecuted. Apart from the ill-defined relation between teaching and research, there is considerable waste of time on routine constructional work owing to the absence of technical assistants and mechanics. This waste has not been recognized by the authorities, and in war-time the demands of munition work and other forms of national service are likely to accentuate the evil by increasing the already acute shortage of qualified assistants.
The fundamental problem of university research is, however, that of widening the front of scientific advance, and while preserving the independence of the research worker and avoiding any regimenta. tion, of securing that the resources available are adequately distributed over the whole field of science, and particularly those branches of knowledge where fundamental advance is most urgently demanded to meet the needs of the nation. Some strategy of scientific advance is imperative if resources are to be maintained unimpaired under peace-time conditions; if they are attenu. ated $\mathrm{n}$ war, it may make all the difference between victory and defeat.

The first steps to some such co-ordinated strategy must come from within the ranks of scientific men themselves. It is a matter which concerns all classes of scientific workers, however effectively some of the stronger groups, such as the chemists, might contribute through their professional organizations to the removal of particular handicaps on efficiency. Through the Royal Society or the new Division for the Social and International Relations of Science of the British Association, something of a plan of advance should be elaborated, taking account of existing gaps in the front of science, the border-line territories which are apt to be neglected and the manifold needs of a society at war and of the reconstruction to follow. Only with such a broad plan as basis will it be possible to compute the effort required, and the extent to which existing resources must be supplemented or diverted.

Given such a plan, some type of executive authority and scientific General Staff will be required to carry it out. The nucleus should not be hard to find in the Advisory Council on Scientific Research and Technical Development and existing organizations. Here, however, as on the economic front, the primary need is for vision and drive. It is only when scientific workers themselves realize the immense possibilities in their hands that we can hope for the elaboration and execution of that plan. From them must come the pressure on their individual societies and associations for the formulation of a common policy, and the resolute attack on all forms of inefficiency and waste in scientific research, and on obstacles to its development. On them individually, too, must rest a large share of the responsibility for making both the Government and the public realize the value of the contribution which science could make and the means by which that effort should be organized and directed. 